\title{
Relationship between SARS-CoV-2 Pandemic and ST-Segment Elevation Myocardial Infarction Frequency
}

\author{
Tuba Ekin, Asım Oktay Ergene \\ Department of Cardiology, Faculty of Medicine, Dokuz Eylul University, İzmir, Turkey \\ ORCID: \\ Tuba Ekin: https://orcid.org/0000-0003-4015-1711 \\ Asım Oktay Ergene: https://orcid.org/0000-0003-1775-4063
}

\section{Abstract}

Background: Previous studies have shown the relationship between respiratory viruses with acute coronary syndromes. However, its relationship with a new virus, severe acute respiratory syndrome coronavirus 2 (SARS-CoV-2), is not clear yet. Aim: Our aim is to investigate the frequency of ST-segment elevation myocardial infarctions (STEMIs) presenting to catheterization laboratories during SARS-CoV-2 pandemic. Methods: As a pilot study, the number of patients with a primary diagnosis of STEMI admitted to the catheterization laboratory with the purpose of primary percutaneous coronary intervention (PCI) between March 15 and April 15, 2020, also known as the $1^{\text {st }}$ month of the pandemic, was determined. This number then has been compared to the same period of 2019 (March 15, 2019, to April 15, 2019). Results: During the pandemic period (March 15, 2020, to April 15, 2020), eight cases were admitted to the catheterization laboratory for primary PCI, due to STEMI. It was determined that 32 patients were admitted to the catheterization laboratory in the same period of 2019 (March 15, 2019, to April 15, 2019). When primary PCI numbers were compared, it was found that there was a $75 \%$ decrease in the number of cases. In 2019, the monthly average of STEMI cases was $25 \pm 8$. Compared to 2019, there was a $65 \%$ reduction. Conclusion: We found that, there was a substantial decrease in STEMI cases during pandemic period, at least in the initial phase.

Keywords: Coronavirus disease 2019 pandemic, severe acute respiratory syndrome coronavirus 2, ST-segment elevation myocardial infarction

\section{INTRODUCTION}

An epidemic of pneumonia, which is thought to have developed due to a new coronavirus in December 2019, was detected in Wuhan, Hubei Province, People's Republic of China.

The World Health Organization named the virus as "serious acute respiratory syndrome coronavirus-2" (SARS-CoV-2) and the disease caused by the virus as coronavirus disease 2019 (COVID-19). SARS-CoV-2, which causes the acute respiratory disease called COVID-19, is a new beta-coronavirus. ${ }^{[1,2]}$ The main feature of SARS-CoV-2 is easily binding to ACE2 receptor found primarily in the lung type 2 alveolar cells, myocardium, proximal tubule of kidney, esophagus, epithelial cells of ilium, and urothelial cells of bladder in humans, which appears to be

Received: 21-05-2020 Revised: 30-05-2020 Accepted: 16-06-2020

Published Online: 27-11-2020

\begin{tabular}{|l|l|}
\hline \multicolumn{3}{c|}{ Access this article online } \\
\hline Quick Response Code: & Website: \\
& http://www.ijcva.com \\
& \\
\end{tabular}

the result of a new mutation. ${ }^{[3]}$ Previous studies have shown that respiratory viruses, especially influenza virus, increase acute myocardial infarction. ${ }^{[4]}$ In patients with chronic atherosclerotic disease, infectious diseases have been shown to cause acute coronary syndrome (ACS) through acute inflammation, biomechanical stress, and vasoconstriction. ${ }^{[4]}$ Infections also create a thrombogenic environment through platelet activation and endothelial dysfunction. Therefore, SARS-CoV-2, one of the respiratory viruses, was also expected to cause increase in ACS events. In this study, our aim was to investigate the relationship between COVID-19 infection and prevalence of ST-segment elevation myocardial infarction (STEMI).

Address for correspondence: Dr. Tuba Ekin, Department of Cardiology, Faculty of Medicine, Dokuz Eylul University, Izmir, Turkey. E-mail: ekin130@hotmail.com

This is an open access journal, and articles are distributed under the terms of the Creative Commons Attribution-NonCommercial-ShareAlike 4.0 License, which allows others to remix, tweak, and build upon the work non-commercially, as long as appropriate credit is given and the new creations are licensed under the identical terms.

For reprints contact: WKHLRPMedknow_reprints@wolterskluwer.com

How to cite this article: Ekin T, Ergene AO. Relationship between SARS-CoV-2 pandemic and ST-segment elevation myocardial infarction frequency. Int J Cardiovasc Acad 2020;6:147-9. 


\section{Methods}

After the first case of COVID-19 was diagnosed on March 11, 2020, Dokuz Eylul University Medical Faculty Hospital was assigned as a pandemic hospital according to the directives of the Ministry of Health, and the elective cardiac procedures were terminated as of March 16, 2020. The number of patients with a primary diagnosis of STEMI admitted to the catheterization laboratory with the purpose of primary percutaneous coronary intervention (PCI) between March 15, 2020, and April 15, 2020, also known as the $1^{\text {st }}$ month of the pandemic, was determined. This number then has been compared to the same period of 2019 (March 15, 2019, to April 15, 2019). In addition, the number of STEMI patients for the whole year before the pandemic was determined and the monthly average of the year was calculated and compared to the period between March 15, 2020, and April 15, 2020.

\section{RESULTS}

During the pandemic period (March 15, 2020, to April 15, 2020), eight cases were admitted to the catheterization laboratory for primary PCI, due to STEMI. It was determined that 32 patients were admitted to the catheterization laboratory in the same period of 2019 (March 15, 2019 to April 15, 2019). When we compare the pandemic period (March 15, 2020 - April 15, 2020, - 8 cases) to the corresponding period in 2019 (March 15, 2019-April 15, $2019,-32$ cases), primary PCI numbers were decreased by $75 \%$ due to STEMI [Figure 1]. The difference was statistically significant. The average monthly STEMI cases for whole 2019 were $25 \pm 8$. When we compare this average to the pandemic period, we detected a $65 \%$ reduction. This reduction was statically significant [Figures 2 and 3].

\section{Discussion}

The first COVID-19 case has been reported on March 11, 2020, in Turkey. As of March 16, 2020, elective cardiac cases were completely stopped and elective cardiac invasive interventions were postponed at Dokuz Eylul University Cardiology Department on the authority of the recommendations of the Turkish Ministry of Health, to reduce the risk of transmission of infection. These measures were also recommended in the consensus report of Turkish Society Cardiology (TSC)

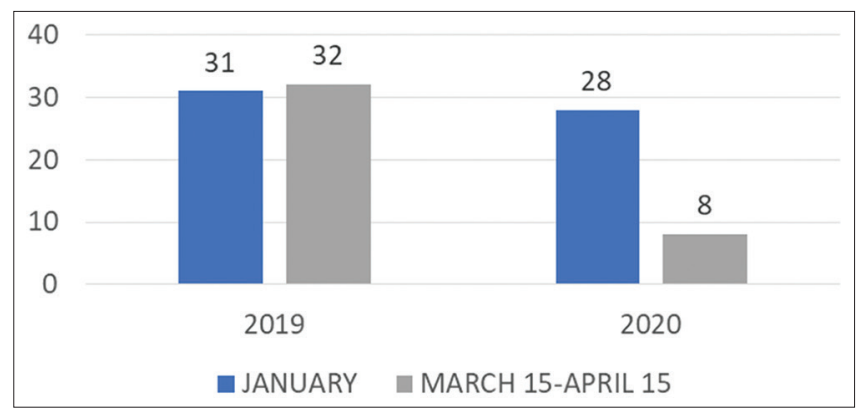

Figure 1: Number of ST-segment elevation myocardial infarction cases who have done percutaneous coronary intervention published during the pandemic ${ }^{[5]}$ According to the current guidelines, the main treatment method in patients with STEMI is primary PCI. ${ }^{[6]}$ Either consensus report of TSC or recommendations from the Peking Union Medical College Hospital for the management of acute myocardial infarction during the COVID-19 outbreak was stated that if the patient is infected or there is a high suspicion of SARS-CoV-2 infection, the primary PCI should be the preferred method, provided that necessary precautions are taken. ${ }^{[5,7]}$ In the early days of the pandemic, fibrinolytic therapy was recommended for STEMI patients. ${ }^{[7]}$ Similarly, in the TSC consensus report, fibrinolytic therapy was upgraded as the treatment to be preferred, especially in patients who do not meet the high-risk criteria. ${ }^{[5]}$

In respiratory tract infections, particularly, in viral infections such as influenza, it is known that there is an increase in the frequency of ACS or disorders that mimic ACS such as myopericarditis. ${ }^{[4]}$ However, in the $1^{\text {st }}$ month of pandemic, we observed that there was no increase in STEMI admissions as expected; instead, there was a decrease in the STEMI cases. Although fibrinolytic reperfusion therapy has not been preferred in any patient in our clinic with STEMI, primary PCI was performed in all patients, and the caseload of our catheterization laboratory was decreased. Between March 15, 2020, and April 15,2020 , only eight STEMI cases were admitted in our clinic, who have undergone for primary PCI. It was significantly lesser than previous months. To make comparisons in terms of seasonal influences, we also compared these figures to primary PCI numbers between March 15 and April 15, 2019. There was a $75 \%$ reduction when compared to the same time frame in the previous year. Similarly, recent publications from pandemic countries have been reported that the numbers of primary PCI for STEMI have decreased significantly. ${ }^{[8,9]}$

It is well known that in respiratory tract infections, particularly in viral pneumonias such as influenza, there is an increase in the frequency of ACS or the disorders that mimic ACS such as myopericarditis. ${ }^{[4]}$ Therefore, an increase in the number of STEMIs during the pandemic period could be expected. Some cases with myopericarditis were reported in COVID-19 pandemic that mimic ACS. However, we observed that there was no increase; instead, there was a decrease in STEMI cases.

Although there are various hypotheses on the reasons for the decline, multicenter studies and careful follow-up are needed to establish the exact cause. In some publications, it is suggested that patients avoid hospital admission because of the risk of infection and it is resulted in mortality in some patients before they reach the hospital. ${ }^{[9]}$ Patients who avoid hospital admission have been exposed to ACS complications, such as heart failure, in the future. Although they are a minority, it is thought that some patients are worried about unnecessarily busy hospitals and emergency medical services. Less exposure to environmental and psychosocial stress factors due to the policy of staying home during the pandemic period and the decrease in smoking can be as the important factors in this decrease. In addition, skipping the diagnosis of STEMI due 


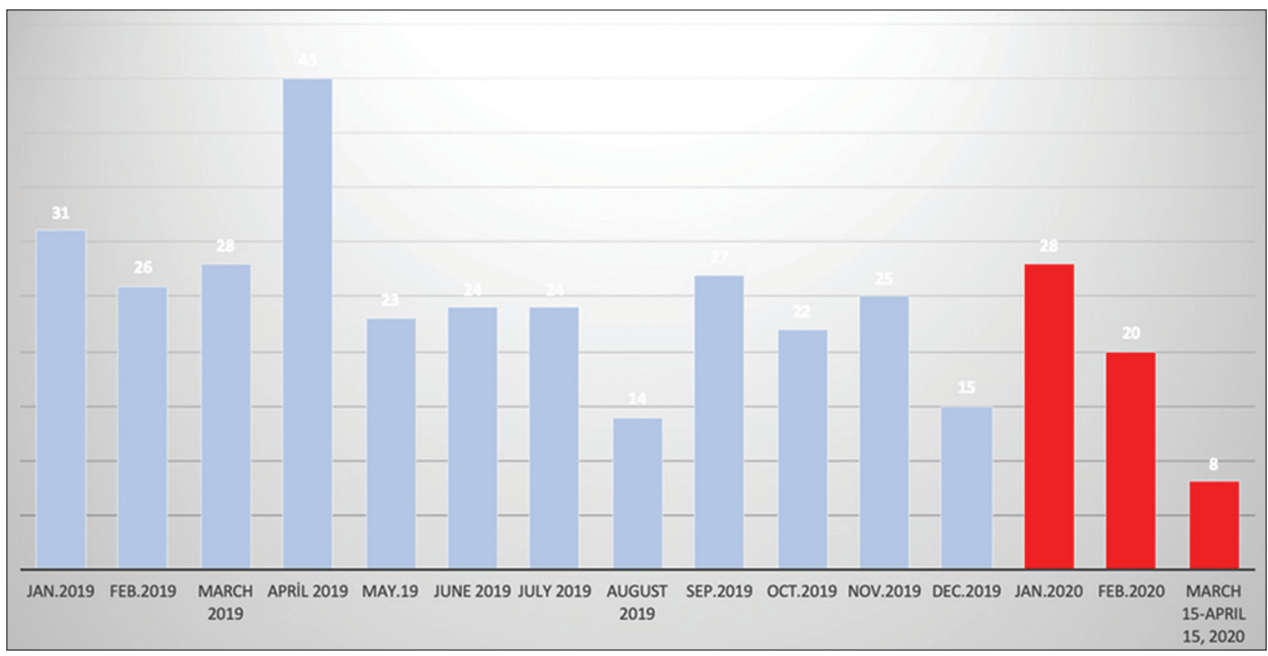

Figure 2: Number of cases compared to the first period of pandemic and 2019 months

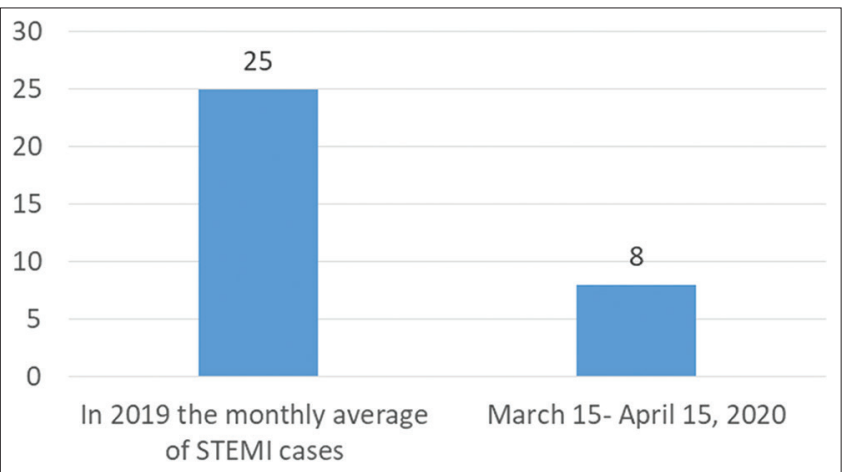

Figure 3: Number of ST-segment elevation myocardial infarction cases before COVID-19 and during COVID-19

to selectivity in the perception of clinicians during pandemics seems to be another possible factor, albeit low. We still do not know the exact reason for this decrease. While the pandemic is still ongoing, we are planning to monitor the caseload of catheterization laboratory in the upcoming months of pandemic to reveal the causes of this decrease.

\section{Limitations}

The most important limitation of our study is that it is a single-center study and the small sample size. Another important limitation is that our study does not provide prognostic information due to the absence of follow-up studies. In the future, a prognostic evaluation can be made with studies with more patients.

\section{Financial support and sponsorship}

Nil.

\section{Conflicts of interest}

There are no conflicts of interest.

\section{REFERENCES}

1. Zhou P, Yang XL, Wang XG, Hu B, Zhang L, Zhang W, et al. A pneumonia outbreak associated with a new coronavirus of probable bat origin. Nature 2020;579:270-3.

2. Naming the Coronavirus Disease (COVID-19) and the Virus that Causes it. Available from: https:/www.who.int/emergencies/ diseases/novel-coronavirus-2019/technical-guidance/namingthe-coronavirus-disease-(covid-2019)-and-the-virus- that-causes-it. [Last accessed on 2020 Mar 23; Last accessed on 2020 Mar 21].

3. Andersen KG, Rambaut A, Lipkin WI, Holmes EC, Garry RF. The proximal origin of SARS-CoV-2. Nat Med 2020;26:450-2.

4. Kwong JC, Schwartz KL, Campitelli MA, Chung H, Crowcroft NS, Karnauchow T, et al. Acute myocardial infarction after laboratory-confirmed influenza infection. $\mathrm{N}$ Engl $\mathrm{J}$ Med 2018;378:345-53.

5. The Consensus Report of Turkish Society Cardiology: Things to know about COVID-19 pandemic and cardiovascular diseases (25 March 2010). Arch Turkish Soc Cardiol 2020;48 Suppl 1:1-48.

6. Endorsed by the Latin American Society of Interventional Cardiology, PCI Writing Committee, Levine GN, Bates ER, Blankenship JC, Bailey SR, et al. 2015 ACC/AHA/SCAI focused update on primary percutaneous coronary intervention for patients with ST-elevation myocardial Infarction: An update of the 2011 ACCF/AHA/SCAI guideline for percutaneous coronary intervention and the $2013 \mathrm{ACCF} / \mathrm{AHA}$ guideline for the management of ST-elevation myocardial infarction: A report of the American College of Cardiology/American Heart Association Task Force on Clinical Practice Guidelines and the Society for Cardiovascular Angiography and Interventions. Catheter Cardiovasc Interv 2016;87:1001-19.

7. Recommendations from the Peking Union Medical College Hospital for the management of acute myocardial infarction during the COVID-19 outbreak European Heart Journal 2020;41:1791-4.

8. Rodríguez-Leor $\mathrm{O}$, et al. Impact of the COVID-19 pandemic on interventional cardiology activity in Spain. REC Interv Cardiol 2020;2:82-9.

9. Garcia S, Albaghdadi MS, Meraj PM, Schmidt C, Garberich R, Jaffer FA, et al. Reduction in ST-segment elevation cardiac catheterization laboratory activations in the United States during COVID-19 pandemic. J Am Coll Cardiol 2020;75(22):2871-2. 